\title{
A revision of communication strategies for effective disaster risk reduction: A case study of the South Durban basin, KwaZulu-Natal, South Africa
}

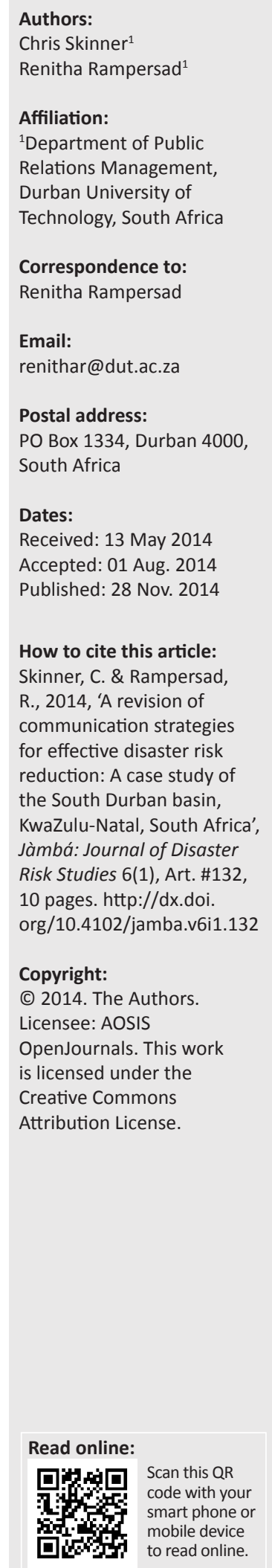

The study examined how effective forms of communication are, or could be, impacting the more traditional forms of emergency and disaster management communication through the print and electronic media and how an integrated communication strategy involving all stakeholders could prove to be successful. This study was of an exploratory and descriptive nature, using a case study of the South Durban basin to demonstrate how media analysis, community discussions and internal and external evaluations of current practices in use by major industrial players in the basin has thus far failed to reach its full potential for effective disaster risk reduction. Strongly emerging from this study was the finding that, as a result of these evaluations, new systems are now being planned to incorporate social media as an integral part of an overall communication strategy, which could have far-reaching implications for corporate communicators and strategic planners.

\section{Introduction}

South Africa, like many other developing countries, is constantly confronted by human-induced disasters. Therefore, in 1994, the South African government actively moved towards the disaster risk reduction paradigm (Republic of South Africa 2005:1) by resolving to:

adopt a new developmental approach in line with global trends by integrating risk reduction methodologies into developmental initiatives to build resilience in households, communities and areas known to be at risk. (Le Roux 2013:2)

The Hyogo Framework 2005-2015 (United Nations Office for Disaster Risk Reduction [UNISDR] 2007) emphasises that:

disaster risk is increasingly of global concern and its impact and actions in one region can have an impact
on risks in another, and vice versa. This, compounded by increasing vulnerabilities related to changing
demographic, technological and socio-economic conditions, unplanned urbanization, development
within high-risk zones, under-development, environmental degradation, climate variability, climate
change, geological hazards, competition for scarce resources, and the impact of epidemics such as
HIV/AIDS, points to a future where disasters could increasingly threaten the world's economy, and its
population and the sustainable development of developing countries. (p. 1) If the process of communication is difficult in our ordinary and daily lives, it is far more so in times of disaster. The challenge remains to not only respond with accurate, understandable and complete information as quickly as possible during a disaster, but also to communicate in a proactive way that involves members of communities to reduce the potential risk of a disaster (Nyondo 2006).

Effective communication management is a critical tool in the management of a disaster (Marlow \& Wilson 1997). Organisations often experience information meltdown during a disaster and this is effectively when management could decide to take total control of all information and only feed through what they consider important, necessary, or 'safe'. Communication is therefore a dynamic process with a twofold purpose that can foster learning, positive change and empowerment. It is a continuous process of coding, decoding and interpretation and a way of sharing objectives, attitudes, knowledge, information and opinions. It takes place in a social context and people take the roles of both source and recipient (Abarquez \& Murshed 2004).

When considering communication for disaster risk reduction, one should take into consideration that context plays a key role. The sociocultural context of the society, gender perspectives and scale of community (rural, small or mega) will determine how communication will be implemented. Communication planning occurs in an organisational context and is embedded in institutional cultures with specific agendas. Moreover, communication takes place in a context of risk 
assessment, risk intervention and risk evaluation, making it a strategy that is executed within disaster risk management. Also, social vulnerability is key to determining the methods of communication and therefore people, complex social systems and non-structural solutions should be analysed (Abarquez \& Murshed 2004). This is in keeping with the general considerations in the 'Priorities for action' within the Hyogo Framework 2005-2015 (UNISDR 2007), where each State has the primary responsibility for its own sustainable development and for taking effective measures to reduce disaster risk. These include ensuring cultural diversity, age, vulnerable groups and a gender perspective are integrated into all disaster risk management policies, plans and decision-making processes through which the State aims to protect its people, territory, infrastructure and other national assets from the impact of disasters.

The 2010 British Petroleum (BP) oilrig explosion, which disgorged millions of gallons of oil into the Gulf of Mexico and challenged the corporate image of $\mathrm{BP}$, is a testament of the communication planning discussed above. In trying to preserve and restore their corporate image, BP used many strategies to alleviate the intensity of the ongoing threat to individuals, businesses and the ecosystem, including various social media channels to interact with individuals and interest groups (Muralidharan, Dillistone \& Shin 2011). Until recently, traditional forms of mass communication were used to disseminate information about 'understanding, surviving, and recovering from natural disasters' (Paul 2001:43). Paul (2001) iterates that relatively recently, the one-way disaster communication model had shifted towards a two-way view. This is especially apparent in how officials and agencies communicate with the general public, who expect up-tothe-minute information regarding a disaster - something now made possible with the advent of the Internet. Paul (2001) suggests that the rapid adoption of new media has led to a shift in how crisis management is practiced (also see Muralidharan et al. 2011).

The above case augments how important effective and transparent disaster communication plans and practices are, especially to mitigate impacts on corporate reputation. In exploring this further, this article focuses on a study of the South Durban basin to demonstrate how media analysis, community discussions and internal and external evaluations of current practices in use by major industrial players in the basin has proved to be successful.

\section{Understanding the South Durban basin}

Although the South Durban basin is considered one of the economic hubs of South Africa, it also continues to be the 'environmental and disaster management hotspot' in South Africa (South Durban Community Environmental Alliance [SDCEA] 2008b:1). In particular, it has a unique spatial plan that has several heavy industries integrated with highly populated residential areas. Whilst these industries are considered as having a positive economic impact, they contribute to several negative impacts in the area, including air and water pollution and poor health conditions in the neighbouring communities, exposing the residents to high risks in events of industrial accidents and malfunctions.

The many activities that contribute negatively to this situation in the South Durban basin are identified as two oil refineries, with a total processing capacity of approximately 250 million barrels of crude oil a day (supplying $60 \%$ of South Africa's total fuel requirements), a paper mill with a processing capacity of 550000 tons per annum, several bulk storage tank facilities which also store hazardous and toxic chemicals in bulk, approximately 300 other industries including the manufacture of chemicals, food and pharmaceutical products and the motor and allied industries (SDCEA 2008a).

Situated on the upper South coast, approximately $20 \mathrm{~km}$ from Durban, and adjoining the South Durban basin lies one of the largest concentration of chemical manufacturing companies in South Africa (Skinner 2012:115). The Umbogintwini industrial complex currently has 13 major operating companies, 12 of which manufacture a variety of chemical products, animal feeds and textiles. The thirteenth, Heartland Leasing, supplies a range of services to the 220 ha industrial site, such as potable water, steam, electricity, laboratory facilities, security, rail and engineering workshops, and is also responsible for maintenance of the site infrastructure (Umbogintwini Industrial Association [UIA] 2013).

Adjacent to this industrial complex are also two new shopping complexes: Arbour Crossing, with an area of $43000 \mathrm{~m}^{2}$ of retail space and over 50 stores, which was opened in 2008, and the Galleria Mall, with over $81603 \mathrm{~m} 2$ of retail space and over 200 stores, which was opened in 2009 (Skinner 2012:116). Together, they handle some 5000 shoppers at peak times, which makes the site the third-largest shopping complex in KwaZulu-Natal. There is no doubt that the proximity of both shopping complexes to the chemical site has added a further dimension to the safety, security and access of emergency services to the area and the need, therefore, for a revised integrated disaster management strategy for this area and the basin as a whole.

The concentration of such a diverse range of industrial and commercial activities, coupled with a residential population living in close proximity to this development, makes it essential that proper planning is undertaken that involves all key stakeholders. Fundamental to all of this is the need for an integrated communication strategy to keep everyone informed, particularly in cases of emergency and disaster management. A communication strategy for disaster reduction and preparedness should include specific communication actions and activities that enable all stakeholders (risk practitioners and development organisations as well as community members) to participate in discussions, share opinions and information and build partnerships. 


\section{Defining communication approaches \\ Disaster risk communication}

Risk communication is as an interactive exchange of information and opinion amongst individuals, groups and institutions, with the goal of assessing, minimising and regulating risks (Ropeik 2008). In essence, it is the sharing of information with the public or institutions about the probability and consequences of harmful events and therefore enables the public to respond to the crisis and reduces the possibility of misinformation. Effective risk communication involves trust between the organisation and people communicating the risk and the audience receiving information.

Abarquez and Murshed (2004) further define risk communication as an interactive process that exchanges information and opinion amongst individuals, groups and institutions. It usually involves multiple messages regarding the nature of the risk and expresses concerns, opinions and reactions to risk messages, or to legal and institutional arrangements for risk management.

Risk communication differs from other communication as it is a political process that can present ethical problems. Moreover, risk communication differs from public awareness, as it not only aims to educate the public on risks but is also a reciprocal process, meaning that different stakeholders listen to each other and form a common understanding about risks, their acceptability and actions to reduce those risks. Also, the aim of risk communication is to ensure agreement between stakeholders on different risk management measures and to improve transparency of decisions and increase the potential acceptance of the outcome (Abarquez \& Murshed 2004; Reynolds 2002).

\section{Communication policy and strategy for disaster risk reduction \\ Communication policy}

Policies define the relative importance and direction of disaster risk reduction in general, the actors, their roles and capacities in communication, their potential forms of organisation and the use of media, channels and infrastructure. They also set rules, direction and the frame for the development of disaster risk reduction communication. Businesses are now shifting their policies to enhance the growth of the communication sector and engaging in cooperative efforts to improve communications. In particular, this increasingly involves the incorporation of information technology and social media within increasingly complex 'communication ecosystems' (Alozie 2011).

\section{Communication strategy}

Strategy, in general, is a systematic, well-planned series of actions, combining different methods, techniques and tools to achieve an intended change or objective utilising the available resources within a specific timeframe. Likewise, a communication strategy is a well-organised sequence of actions to achieve specific objectives through the implementation of a mix of communication methods, techniques and approaches. When a communication strategy is designed for disaster reduction and preparedness, it should address and solve problems especially at community level through using research findings, communication methods, techniques and media (Okada \& Matsuda 2005). These authors further propose that communication strategy for disaster preparedness and reduction should follow a multilateral knowledge development approach as this will increase disaster preparedness at community level and allow stakeholders to share their knowledge, which leads to a continuous improvement of the risk communication process (Okada \& Matsuda 2005).

A communication strategy for disaster reduction and preparedness should include specific communication actions and activities that enable all stakeholders (risk practitioners for non-profit relief and development organisations as well as community members) to participate in discussions, share opinions and information and build partnerships. Although communication methodologies have already been established to address disaster reduction, there is still an acknowledged need to improve and adapt existing strategy possibilities for community-based disaster preparedness. A multilateral knowledge development process could address this gap (Okada \& Masuda 2005).

Thus, when a communication strategy for disaster reduction is formulated, be it either for public relations, media relations or advocacy, the strategy should involve a communication mix that encourages and enables knowledge exchange and the empowerment of the members of communities to take action in preparing for and reducing the risk of disasters. Also, in determining the communication mix, one should recognise the differences amongst media (print vs broadcast, radio vs television, domestic vs international) and thus take into account each one's distinct and potential characteristics (Cate 1994).

\section{Communication context within the South Durban basin}

There is one overall communication strategy for the South Durban basin as a whole as set out in the eThekwini disaster management plan (eThekwini Municipality 2011). This is currently being revised in consultation with the main players in the region. Individual large operators such as Mondi, Engen and Sapref also have their own emergency and disaster management plans, as do the businesses that form part of the Umbogintwini industrial complex. These are fully integrated into the eThekwini master plan. There are, however, no early warning siren and public address systems installed in the residential areas of the South Durban basin. 
Public education programmes currently inform the public to go inside and turn on their radios. The primary means of communication with the public is therefore currently through local radio stations:

- East Coast Radio - from FM 93.9 MHz to 96.95 MHz.

- Ukhozi - from FM 90.8 MHz to 107.4 MHz.

- Lotus - from FM 87.6 MHz to 90.6 MHz.

- Gagasi - FM 99.5 MHz.

Essentially, the messages that are broadcast inform the public about what the hazard is, what they should do and what they should avoid doing. The notification messages are sent from the disaster operations centre (DOC) of the eThekwini Municipality. However, should the circumstances pose an immediate danger to an affected area then messages are sent from their emergency operations centre (EOC).

Various emergency messages and updates are prepared by the disaster management team and made ready to fax or email to the local radio stations and public media. These cover the first warning of an impending disaster, updating of messages as the situation develops, giving notification of evacuation and transport arrangements if these are necessary and, finally, giving the all clear. All messages are drafted according to the nature and circumstances of each emergency incident. Contact details of all important stakeholders are regularly updated so that information can be transmitted timeously and effectively.

\section{Public protective strategy}

The two basic public protection strategies currently in place in the South Durban basin are evacuation and sheltering-inplace. As part of the emergency response, the public must be adequately informed and advised of which strategy is being adopted for that particular incident. The concept of shelteringin-place involves seeking to limit an individual's exposure to hazardous materials by having them seek refuge within a relatively contained environment. This refers to leaving residents in the protection of their homes with instructions to close windows and doors, shut down outside vent systems and other agent-excluding precautions. Under certain conditions, however, evacuation is the preferred protective action. This is subject to evacuation being accomplished prior to reaching the tip-over point of exposure risk. During some hazardous material releases, there will not be enough time to evacuate because airborne toxicants have been released and are travelling rapidly downwind.

According to the DOC, depending on the nature of the emergency, the decision to evacuate or shelter-in-place will be site driven. This means that it must be decided and coordinated on site at the EOC. If the city's DOC is activated and is in operational mode then they will liaise with the EOC in terms of who takes responsibility for managing the public protection plan. In most circumstances, sheltering-in-place will be the preferred protective action and amounts to a 'goin, stay-in, tune-in' advisory to the affected communities. According to the planners, sheltering-in-place must be seen as the preferred option for the following reasons, particularly in the case of shopping areas which are close to possible hazards, as in the case of Arbour Crossing and the Galleria Mall in Amanzimtoti:

- Evacuation will cause higher than normal traffic flows and this creates the need for traffic direction and control. However, even under ideal conditions, the movement of traffic can result in gridlocks. When combined with the complications of major emergency conditions, moving traffic out of the area is extraordinarily challenging, probably introducing citizens to additional exposure periods and further risk types. Congested conditions could defeat the purpose of evacuation.

- Arrangement for resources such as buses will be time consuming and will leave people stranded in open areas, which will heighten the extent of exposure.

- The needs of special populations such as the nonambulatory, the elderly and people with disabilities will further tax available resources. Vulnerable populations may sustain more injury during evacuation than they would by staying inside and putting simpler counter measures in effect.

- Dislocation and the potential hazard-related dangers people may be facing are likely to place them under considerable stress. People may be unwilling to leave their property.

- The response and exposure durations need to be considered, especially where the risk may have passed the evacuees prior to evacuation.

These two public protection policies have been examined in detail with regard to the risks presented at Umbogintwini, where the two major shopping complexes are located, and it has been found that although procedures are in place, should an accident occur at the chemical complex, extraordinary circumstances could arise that will place the authorities in a very difficult situation to both access the site and handle the emergency at the shopping complex.

In reviewing the off-site emergency plan for the South Durban basin, it is to be welcomed that the authorities are about to embark on a risk assessment survey that will inform on risk reduction strategies, which, in turn, will assist with effective disaster management planning for the region. In addition, the establishment of a municipal disaster management advisory forum for the purposes of external stakeholder participation should also go a long way in improving communication and more transparency in communications between all parties resident and operating in the basin. Unfortunately, the lack of such cooperation and openness in the past has led to conflict and opposition from those residents most affected by the industrial development that has taken place in the area.

\section{The South Durban on-site emergency plans}

In addition to reviewing the South Durban off-site emergency plan, the individual roles and responsibilities of some of the other major players in the basin are examined in this article 
and the plans of Engen and the UIA have been selected as examples. The Engen case study is of particular interest as it demonstrates how a major emergency was handled and, in the case of the UIA, what potential risk(s) could be faced by the organisation and authorities in addition to the local populations.

\section{Engen oil refinery}

The Engen refinery has been in operation for more than 50 years and, during this time, has been one of the major suppliers of petroleum products to the South African market. In recent years, it has experienced a number of major explosions, one of the most serious being in November 2007 when approximately 7.5 million litres of petrol caught fire and burned on account of a lightning strike (Skinner 2012:119). The response to the November 2007 incident was two-pronged - Engen and eThekwini Municipality - with the Municipality forming part of this disaster response because of the existence of extensive residential communities in close proximity to the refinery. Engen's initial response was to send in its specially trained fire fighters who specialise in fuel tank fires. The company also brought in the eThekwini Metro Fire Department, as well as the Municipality's disaster management crews to assist and advise residents to stay indoors and keep windows closed (Skinner 2012). These crews worked in tandem with Engen's disaster team to respond to the crisis.

Community reaction to the disaster was swift. Residents of the communities accused Engen of gross negligence and of not having a crisis management plan activated. They also accused the Municipality of attempting to minimise the damage and the environmental and health effects of the chemical fire on the community. In interviews with various news organisations, some residents said that when they contacted Engen's environment office, they were rebuffed. So, rather than heed Engen's warning to stay indoors, most residents fled their homes. The Municipality was also not forthcoming with information. A resident of one of the communities noted in a news report, that they had never been given a crisis management plan by either the Municipality or Engen:

I've sat on different community forums and the issue of a disaster management or evacuation plan has been brought up numerous times, but the Municipality hasn't assisted us with any information. (Naidu 2007:1)

Whilst Durban city manager at that time, Dr Mike Sutcliffe, acknowledged the existence of a crisis management plan, his response to media inquiries did not assuage the fears of the community. Sutcliffe said:

The city does have a disaster management plan, but each disaster has a different level of operation. We can't always use the same procedure, so it is not something that can be placed on paper and handed out to residents. (Naidu 2007:1)

This negative community reaction indicates that Engen, rather than being proactive, had to activate its plan to reassure the general public, and in particular the local residents, in reaction to negative criticism and that this late response could not be sufficient to repair the damage already caused. Both Engen and the Municipality only embarked on various communication strategies in the aftermath of the disaster. They agreed:

- To provide information (facts) on what had happened in the various accidents and what steps were being taken to improve safety and security at the plant.

- To deploy emergency services to the disaster scene as speedily and efficiently as possible when called upon to do so (Skinner 2012).

Engen used conventional media to disseminate information on the possible causes of the accident and also nonconventional media (mobile public address system) to reach the affected communities. The Municipality, working with Engen, used the same conventional and non-conventional media to communicate to the residents of the communities surrounding the refinery (Skinner 2012).

Engen sent press releases to local and regional newspapers and radio stations about the chemical fire accident which had occurred. The release gave information on the nature of the accident and its possible causes. Throughout this post-crisis period, the company continued to disseminate media releases and to make the refinery manager available for special interviews. This constant communication was designed to update the public on what progress was being made in the plant investigation into the causes of the accident and what subsequent action was being taken to return to normal operations (Skinner 2012). These approaches are broadly in line with the recommendations of the Hyogo Framework (UNISDR 2007) for response and recovery programmes, although they were clearly put into operation too late and as a response to a crisis rather than following a risk reduction strategy understood and agreed to by all stakeholders in advance.

The response to this, and a subsequent chemical accident at the same refinery on 13 November 2008, generated a lot of discussion in radio talk shows and letters to the newspapers (Skinner 2012). The responses also included an open letter to Dr Mike Sutcliffe, released by the chairman of the SDCEA, Mr Desmond D'Sa, entitled 'IVS incident fails to produce emergency plan', in which he criticised the lack of an emergency response plan for the area (SDCEA 2008a). Additionally, with foreign funding, the SDCEA produced a special community brochure to advise its members towards practical steps they should take in case of emergency (Skinner 2012). A number of community meetings were also convened during this period to discuss the way forward and regular contact was maintained between the community and the Engen Community Liaison forum. The latter has been in operation for several years and focuses largely upon the needs of the community and their communication to major industry players for the purpose of informing corporate social investment initiatives. Its function had, up to this time, not been involved in disaster response or disaster management issues. 


\section{Lessons to be learned}

Although the Engen incident described above occurred in 2007, there have been subsequent explosions in 2008 and 2011 and the relationship between Engen and its neighbouring communities has remained strained. The company's community liaison forum has been at the forefront of attempting to forge closer relationships between Engen and local communities, particularly to respond to community needs in the field of health, education and social amenities. There are opportunities too for discussion at the annual review of the licence to operate when the company prepares an annual report to the authorities, in this case the eThekwini Municipality, for its continued plant operations. All stakeholders are invited to be present on this occasion and questions are often asked of both a technical and environmental nature that test the company's credibility, reliability and willingness to make the environment more safe and secure.

\section{Umbogintwini industrial complex}

The UIA is responsible for managing and developing the Umbogintwini industrial complex site. Its aim is to promote the interests of the member enterprises with respect to safety, health and environmental issues. To achieve this, a set of rules and guidelines have been developed to which all businesses and tenants are expected to adhere. These are documented in the UIA manual and include the expectations on control of liquid effluent, gaseous emissions, control of hazardous materials and the minimisation of impacts on surrounding communities, on wildlife and the environment in general (UIA 2010).

The UIA committee currently consists of seven trustees who manage all UIA site interests, unless a broader UIA forum involvement is deemed necessary. They manage the interactions with the surrounding communities using mechanisms of communication chosen by those communities. This was initially managed through the community awareness and emergency response committee. However, the changing nature of the communities as the area developed has demanded a more inclusive approach, resulting in that committee being replaced by the sea and air emissions focus groups and the stakeholders' forum. All potential developments on the site are presented to stakeholders at the forum meetings, so that they can be made aware of any potential safety, health and environmental impacts and whether environmental impact assessments are required.

Information on the site activities is imparted to the broader public through the Hlanganani, an insert that is distributed in several local newspapers three times a year. A community liaison officer has also been appointed by the UIA to facilitate communications with surrounding communities. These include the stakeholder forum meetings, press releases, newsletters, school visits and tours of the complex and community presentations.
The UIA has also developed a well-planned emergency procedure (EMPRO) to deal with on-site emergencies and those that have the potential to escalate off site. Each major enterprise in the complex has its own emergency action plan to deal with emergency situations occurring within its own plant area. The EMPRO alarm is sounded by the complex at the specific request of an on-site company that has an emergency it believes it cannot manage internally and requires the services provided by the EMPRO. There is an EMPRO control room situated at Central gate which comprises a main control room, a communication centre and a joint operations centre (JOC). The Heartland EMPRO team coordinate emergency activities from this control room. According to the officially agreed plan, this will involve providing centralised communication for all responding groups via radio, communicating with the schools and local institutions on how to respond to the emergency, responding to queries from the public, acting as a conduit for additional resources should they be required and assisting with media enquiries.

If an incident escalates beyond the boundaries of the Umbogintwini Industrial Complex (UIC), the disaster management plan (eThekwini Municipality 2011) will be activated. In such an event, national, regional and local government agencies, under the guidance of the eThekwini Municipality Disaster Management Department, will manage the emergency response using the JOC as the centre of operations.

\section{The South Durban off-site emergency plan}

A consulting agency appointed by the eThekwini Municipality is undertaking a comprehensive risk assessment of the South Durban basin area, which will assist in the implementation of risk reduction strategies and disaster management planning. As shown above with regard to Engen and the UIC, industries operating within the basin have their own on-site emergency plans that include internal response capability. These plans also detail the roles and responsibilities of municipal and other government and private agencies in case of emergencies. The off-site emergency plan is an extension of the particular industries' on-site plans and, in most instances, the off-site consequences will be managed by the on-site EOC, also referred to in some plans as the JOC, or emergency headquarters.

The initial management of off-site consequences by the EOC is based on two critical factors, namely:

- Key municipal staff should be on scene at both the forward command post, as well as at the EOC, prior to the DOC being activated.

- If immediate action is required, then the EOC on-site command personnel will be first on scene to coordinate overall strategy in dealing with the emergency. 
Where circumstances dictate, the Municipal Disaster Management Centre, namely the DOC based in central Durban, will be activated.

Further to the above, the Disaster Management Act (Act 57 of 2002) (Republic of South Africa 2002) assigns discretion as to whether a Metropolitan Council constitutes formal structures such as a municipal disaster management advisory forum for the purposes of external stakeholder participation. The eThekwini Municipality has elected to establish the necessary institutional arrangements to give effect to this discretionary power, thereby endorsing the principles of cooperative governance and interdepartmental cooperation by establishing such a forum (eThekwini Municipality 2011). This advisory forum constitutes a collaboration between a range of stakeholders from key sectors including government, business and academic and civil society, to support and enhance the Municipality's efforts to reduce risk where possible and to assist in the development of action plans to address all aspects of disaster risk reduction. The advisory forum has established a multidisciplinary technical task team, dedicated to the ongoing review of the off-site emergency plan for the South Durban basin. Thus, should a major emergency or disaster occur or threaten to occur in future, this will trigger a multidisciplinary and multidimensional response to re-establish normality.

\section{Outcomes assessment}

At least twice a year, incidents based on the major potential risks of selected site enterprises are simulated to test the internal emergency action plans as well as the site emergency procedure. All parties engaged in the exercise get together immediately after the mock emergency to discuss strategy and tactics and evaluate the success of the emergency operations. In particular, they review:

- How the emergency was handled at plant level.

- How well the external forces of ambulance, fire and other emergency services called in to assist coordinated their efforts.

- How the emergency was communicated with key stakeholders such as schools, hospitals and old age homes that may be affected by the accident.

- How the general public were informed through local media.

These exercises are open to the public and centre on a brief mock emergency within one factory or industrial site within the complex in order not to interrupt normal production. Overall, however, there appear to be gaps between the good intentions illustrated above and genuine communication with the community or with community organisations. These have been recorded particularly by the SDCEA, coordinated by the executive director, Desmond D'Sa, and it is significant that this organisation has received national and international acclaim as a community liaison initiative. As D'Sa explains, the eThekwini authorities have commissioned consultants to get feedback from the key role players in the South Durban basin about a revised emergency disaster plan for the region:
However, this is more than two years ago and although key players such as SDCEA have been consulted, they have not produced a master plan for final discussion and approval. Also no mention is made in the initial document of the potential use of social media in a communication context, just the role of traditional media particularly the use of local radio. What is also of significance is that Engen and Sapref are not using any social media to inform communities of any incidents. (D. D'Sa pers. comm., 11 July 2014)

In contrast, the SDCEA uses social media almost exclusively within minutes to inform its members of the time, location, possible causes and consequences of the disaster and what action or precautions the community should take in the circumstances.

In reviewing the strategies discussed, it is clear that organisation's websites could be more interactive with regards to both the media and the community; in particular, social media could play a much more important role in the overall communication strategy.

\section{The role of social media in disaster management}

The emergence of the popularity of social media has changed the practice of communication in South Africa and globally and, increasingly, its significance in the area of disaster management is being recognised (e.g. International Federation of Red Cross and Red Crescent Societies [IFRC] 2013). Because of the high importance organisations place on social media, as well as its growing popularity amongst various publics, businesses are becoming more involved in trying to measure and manage social media (DiStaso, McCorkindale \& Wright 2011). This has seen a change in the relationship between a business and its employees, customers, competitors, suppliers, investors, the media and essentially everyone who has an impact on, or who can be impacted by, an organisation (Yang \& Lim 2009).

Social media is defined as 'anything that uses the Internet to facilitate conversations' (Solis \& Breakenridge 2009:n.p.); it encompasses tools that can be used to build relationships through open dialogue internally and externally, providing both opportunities and challenges (DiStaso et al. 2011). In their 2010 study, Wright and Hinson found that most (81\%) public relations professionals believed that social media offered organisations low-cost ways to impact organisational transparency (Wright \& Hinson 2010). This is clearly significant in relation to the communication strategies that industry players are in a position to employ during, and in the aftermath of, disasters.

Although there are many definitions of social media, it is interesting to differentiate between social networking (e.g. Facebook), social bookmarking (e.g. Digg), video-sharing (e.g. YouTube), picturesharing (e.g. Flickr), professional networking (e.g. LinkedIn), user forums, blogs and microblogging (e.g. 
Twitter). A number of the more established social media channels enjoy some of the highest traffic on the Internet. The reasons for their popularity are undoubtedly varied, but a key feature is that they allow an unprecedented opportunity for individuals to engage in social interactions on a scale, and in a way, that was previously not possible (Fishcher \& Reuber 2011).

In recent years, the Internet has become a primary source of emerging information about disasters (Noack 1997) and previous international cases, such as the California wildfires (Sutton, Palen \& Shklovski 2008), heavy rainfall in Palo Alto, California (Zinko 2000) and the Los Angeles earthquake (O'Reilly \& Milstein 2009), have shown that it is a useful tool for those affected in times of crisis. Paul (2001) suggested that the rapid adoption of new media has led to a shift in how crisis management is practiced. Social media and its various manifestations, including social networks, microblogs, mobile text messages, and Rich Site Summary (RSS) feeds have emerged from a novelty a few years ago to an important and sophisticated set of contemporary communication tools (also see Muralidharan et al. 2011). This was significantly highlighted in the handling of the 2010 Haiti earthquake.

There are three reasons why the public turn to social media in moments of need or disaster, namely bandwidth, response and power. If there is a very limited amount of time, battery life, or other opportunity, one can reach unlimited numbers of people that can help by posting to social media. People expect a response on social media as it is a social space where engaging and interaction is the constant action. Thus, if help or support is needed, the community will take action. Increasingly, local self-help situations are developing that involve businesses and the victims of disasters: "'Do it yourself" approaches are challenging traditional humanitarian organisations' (IFRC 2013:64), but ideally both should be linked.

Usually during disasters, one or other communication channel breaks down and is not operational. One of the biggest advantages of social media is that it can be accessed through computers as well as smartphones. Cloud computing allows for backups to be safely stored and solar chargers can overcome power outages (Gladstone Observer 31 July 2012:2). With further technological advances, social media will soon be integrated with offerings such as Google TV and Apple TV to offer another medium to reach out to mass audiences (Idugboe 2011). Its use has also been harnessed in hurricane-related emergencies, such Hurricane Sandy in New York in 2012. The World disasters report (IFRC 2013:61) explains the innovation in preparedness with the development of preparedness apps, which are unique in being able to add content in direct response to users' needs. This first proved its value after the Haiti earthquake, allowing for health professionals to identify pockets of need and to respond accordingly (IFRC 2013:61). In South Africa, social media, such as Facebook, Twitter, Mxit and other relevant sites, could be used to build relationships and engage in conversations with the community and not only to communicate with them when there is a disaster!

\section{Conclusion}

Recent research (e.g. Enia 2013; Kirton 2013; Mabaso \& Manyena 2013) both within Africa and globally indicates that the full potential of the use of social media in disaster situations is far from fully realised as yet - and also that there are structural barriers, both economic and political, to its implementation. Recent research in sub-Saharan Africa (Mabaso \& Manyena 2013) finds that there is a wide gap between theory and practice in contingency planning, with these strategies remaining purely theoretical at present; whilst the Hyogo Framework, formulated as long ago as 2005, has so far been found to be patchy in its implementation (Enia 2013). Disaster management as a public good is necessarily prone to the problems of resourcing associated with 'the tragedy of the commons' and most especially in developing countries (Enia 2013). The situation in South Africa will necessarily be affected by some of these structural barriers, but, as a middle-income country, the potential for success here is greater.

In this case study of the industrial sites encompassing the South Durban basin and its adjacent industrial complex, it is clear that some of the lessons from these emerging practices are being learnt by municipal authorities, industry players and the community. There is recognition of the need to link disaster management to development goals, as required by the South African Disaster Management Act (Republic of South Africa 2002), to engage the community and to move from an approach of response to one of risk reduction. It appears that the need to recognise the full complexity of current information 'ecosystems' and their potential role in preparing for, and in mitigating, disasters is, however, better appreciated by the community and, particularly, by the SDCEA than by the industrial enterprises in the area.

What corporate communicators therefore need to provide, beyond good information about their products and services, are communication services that enhance their corporate responsibility roles, particularly in the field of disaster management. Messages need to be not only clear and concise but also transparent, accurate and proactive. In today's business climate, it is even more important for practitioners to monitor and engage in newsgroups, forums, bulletin boards and other social media. The tools are now available for integrated communication at all levels. In emergencies, close contact needs to be maintained from the onset to the 'all clear' and through the recovery phase, through a combination of radio, cell phones and computers - via websites and social media.

Stakeholders on Twitter could provide updated information and could direct the authorities to those in the community that need immediate attention, as happened in the Haiti disaster, if on a smaller scale. Twitter gains from its immediacy and also because most people can tweet from their mobile phones. Increasingly, Twitter has been the 'first responder' in many disasters, so it is the responsibility of businesses to build up their Twitter followers and ensure that these include a large spread of stakeholders, including journalists. The challenge is 
to create searchable Twitter posts using identifiable hashtags. Both industry players and local government authorities could employ social media such as Facebook, Twitter, Mxit and other relevant sites to build relationships, to engage in conversations, to educate and prepare the community in advance and not only to respond in cases of emergency. Those on Facebook could be provided with current information and could see the emergency plans being put in place via Facebook pages. They could also comment or post enquiries. Businesses will appreciate that ongoing monitoring of the Internet is also needed to identify hostile messages, to correct information that has been misquoted, wrongly excerpted or fabricated, so that misperceptions are rectified before they become damaging. However, whilst monitoring messages for abuse, businesses must be prepared equally to accept negative criticism, respond and rectify situations appropriately if genuine relationships of trust are to be established.

What has happened in the past is that businesses and the SDCEA have worked independently, with little coordination of effort, and the local radio station, East Coast Radio, has been the principal source of external communications. Depending on the emergency, one could now ask the radio station to run a newsfeed from the affected business or industry's Twitter account on their website. The radio would announce this when they broadcast any news of an impending or existing emergency. Again, one of the key sources of information for journalists is the organisation's website and it is best to carry full information about any crisis on the site. This means that the webmaster must be part of the crisis plan and key information made available to him or her as a matter of urgency.

What is clear from both published and current research is that, for better or worse, the Internet can prove to be a double-edged sword. Because of its reach, speed and interactivity it can destroy an organisation's image and credibility, or be a useful tool to manage its reputation and help it respond to crises. 'The winners will be those organisations that most effectively employ social media in honest two-way communications through a long term trustworthy relationship as part of strategic communications' (Wells 2012:538). What this does require, however, is for all parties to be both responsible and committed to serve the interests of all those involved in crises and for there to be the political will to carry policies through to fruition.

\section{Acknowledgements Competing interests}

The authors declare that they have no financial or personal relationships that may have inappropriately influenced them in writing this article.

\section{Authors' contributions}

C.S. (Durban University of Technology) was the project leader and initiator of the research project and drafted the original manuscript. R.R. (Durban University of Technology) was responsible for the project design and concept.

\section{References}

Abarquez, I. \& Murshed, Z., 2004, Community-based disaster risk management: Field practitioner's handbook, Asian Disaster Preparedness Center, Bangkok.

Alozie, E.C., 2011, 'What did they say? African media coverage of the first 100 days of the Rwandan crisis', in A. Thompson (ed.), The media and the Rwanda genocide, pp. 211-230, Pluto Press, London, viewed 10 May 2011, from http://www.idrc.ca/ EN/Resources/Publications/openebooks/338-0/index.html

Cate, F.H., 1994, International disaster communications: Harnessing the power of communications to avert disasters and save lives - The role of media in disaster mitigation, Roundtable on the Media, Scientific Information and Disasters: World mitigation, Roundtable on the Media, Scientific Information and Disasters:
Conference on Natural Disaster Reduction, 23-27 May, Yokohama, Japan.

DiStaso, M.W., McCorkindale, T. \& Wright, D.K., 2011. 'How public relations executives perceive and measure the impact of social media in their organisations', Public perceive and measure the impact of social media in their organisations', Public
Relations Review 37, 325-328. http://dx.doi.org/10.1016/j.pubrev.2011.06.005

Enia, J., 2013, 'The spotty record of Hyogo Framework for Action: Understanding the incentives of national disaster politics', The Social Science Journal 50(2), 213-224. http://dx.doi.org/10.1016/j.soscij.2012.12.004

eThekwini Municipality, 2011, eThekwini disaster management plan, eThekwin Municipality, Durban.

Fischer, E. \& Reuber, A.R., 2011, 'Social interaction via new social media: (How) can interactions on Twitter affect effectual thinking and behavior?', Journal of Business Venturing 26, 1-18. http://dx.doi.org/10.1016/j.jbusvent.2010.09.002

'Social Media Superstars', 2012, Gladstone Observer, 31 July, p. 2.

Idugboe, D., 2011, Why businesses should use social media for disaster management, viewed 05 May 2013, from http://smedio.com/2011/02/24/why-businessesviewed 05 May 2013, from http://smedio.com/
should-use-social-media-for-disaster-management/

International Federation of Red Cross and Red Crescent Societies (IFRC), 2013, World disasters report: Focus on technology and the future of humanitarian action, IFRC, Geneva, viewed 30 June 2014, from http://www.ifrc.org/PageFiles/134658/ WDR\%202013\%20complete.pdf

Kirton, M., 2013, Caribbean regional disaster: Response and management mechanisms, The Brookings-London School of Economics Project on Internal Displacement, London.

Le Roux, T., 2013, 'An exploration of the role of communication during the in-crisis situation', Jàmbá: Journal of Disaster Risk Studies 5(2), Art. 67, 9 pages. http:// dx.doi.org/10.4102/jamba.v5i2.67

Mabaso, E. \& Manyena, S.B., 2013, 'Contingency planning in southern Africa: Events rather than processes', Jàmbá: Journal of Disaster Risk Studies 5(1), Art. 95, 8 pages. http://dx.doi.org/10.4102/jamba.V5i1.95

Marlow, E. \& Wilson, P., 1997, The breakdown of hierarchy: Communicating in the evolving workplace, Butterworth Heinemann, Boston.

Muralidharan, S., Dillistone, K. \& Shin, J.H., 2011, 'The Gulf Coast oil spill: Extending the theory of image restoration discourse to the realm of social media and beyond
petroleum', Public Relations Review 37, 226-232. http://dx.doi.org/10.1016/j. petroleum', Public Relc
pubrev.2011.04.006

Naidu, R, 2007, 'Durban refinery damage hits R120m', Independent Online, 21 November, viewed 05 February 2013, from http://www.iol.co.za/news/southafrica/durban-refinery-damage-hits-r120m-1.379721

Noack, D., 1997, 'Online coverage of the floods', Editor \& Publisher 130(19), 26-27.

Nyondo, R., 2006, 'The role of media in disaster management', Paper presented at African Universities Congress, Khartoum, Sudan, 14-25 January, viewed 02 May 2013, from http://www.dimarsi.org/enn/lib7.htm

Okada, N. \& Matsuda, Y., 2005, 'Risk communication strategy for disaster preparedness viewed as multilateral knowledge management', Systems, Man \& Cybernetics 1 640-647. http://dx.doi.org/10.1109/ICSMC.2005.1571219

O'Reilly, T. \& Milstein, S., 2009, The Twitter book, O'Reilly Media, Sebastopol.

Paul, M.J., 2001, 'Disaster communication on the Internet: An examination of 12 disaster-relief web sites', Journal of Applied Communications 85(1), 43-60.

Republic of South Africa, 2002, Disaster Management Act (Act No. 57 of 2002), Government Printers, Pretoria.

Republic of South Africa, 2005, The National Disaster Management Framework, Notice 27534 of 2005, Government Printers, Pretoria.

Reynolds, B., 2002, Crisis and emergency risk communication, Centers for Disease Control and Prevention, Atlanta.

Ropeik, D., 2008, 'Risk communication: More than facts and feelings', IAEA Bulletin 50(1), viewed 06 October 2014, from http://www.iaea.org/Publications/ Magazines/Bulletin/Bull501/Risk_Communication.html

Skinner, J.C., 2012, 'Hotspot: South Durban basin, South Africa - The Engen oil refinery', in A.M. George \& C.B. Pratt (eds.), Case studies in crisis communication: International perspectives on hits and misses, pp. 113-130, Routledge, New York.

Solis, B. \& Breakenridge, D., 2009, Putting the public back in public relations, Pearson, Upper Saddle River.

South Durban Community Environmental Alliance (SDCEA), 2008a, Emergency planning guide for the people of South Durban, SDCEA, Durban.

South Durban Community Environmental Alliance (SDCEA), 2008b, Spatial and development vision for the people of South Durban, SDCEA, Durban.

Sutton, J., Palen, L. \& Shklovski, I., 2008, 'Backchannels on the front lines: Emergent use of social media in the 2007 Southern California fire', Proceedings of the
Information Systems for Crisis Response and Management Conference (ISCRAM), Washington, DC, 04-07 May. 
Umbogintwini Industrial Association (UIA), 2010, Safety, health \& environment report 2010, UIA, Durban.

Umbogintwini Industrial Association (UIA), 2013, Safety, health \& environment report 2013, UIA, Durban.

United Nations Office for Disaster Risk Reduction (UNISDR), 2007, Hyogo Framework for Action 2005-2015. Building the resilience of nations and communities to disasters, ISDR, Geneva, viewed 28 June 2014, from http://www.unisdr.org/we/

Wells, R., 2012, 'Tying it all together', in A.M. George \& C.B. Pratt (eds.), Case studies in crisis communication: International perspectives on hits and misses, pp. 538-539, Routledge, New York.
Wright, D.K. \& Hinson, M.D., 2010, 'An analysis of new communications media use in public relations: Results of a five-year trend study', Public Relations Journa $4(2), 1-27$.

Yang, S.U. \& Lim, J.S., 2009, 'The effects of blog-mediated public relations (BMPR) on relational trust', Journal of Public Relations Research 21(3), 341-359. http:// dx.doi.org/10.1080/10627260802640773

Zinko, C., 2000, 'Flood watch system put to the test/Palo Alto's website records creek size', San Francisco Gate, 16 February, viewed 09 June 2013, from http:// www.sfgate.com/bayarea/article/Flood-Watch-System-Put-To-the-Test-PaloAlto-s-2803146.php 